\title{
A LIDERANÇA NO FEMININO: UMA REVISÃO DA LITERATURA
}

\section{LEADERSHIP IN THE FEMALE GENDER: A LITERATURE REVIEW}

\author{
Sandrina Sobral ${ }^{1}$ \\ Célia Ribeiro ${ }^{2}$
}

\begin{abstract}
Resumo: A liderança surge como uma temática vastamente estudada nas várias publicações científicas nacionais e internacionais. Nesse sentido, importa averiguar se a liderança no feminino merece destaque idêntico. Objetivou-se analisar a produção científica publicada na biblioteca online do conhecimento (b-on) entre $2010 e$ 2017, inclusive. Para tal foram analisados 20 artigos, em resultado da limitação da pesquisa através das palavras-chave "liderança", "feminina" e "género". A maioria dos estudos revelaram-se descritivos, qualitativos, exploratórios e de cariz transversal, com a recolha de dados a ser efetuada através de entrevistas, e a análise de conteúdo como método de tratamento de informação. Os estudos focaram-se nas dificuldades de ascensão feminina a cargos de hierarquias superiores, bem como nas suas características e estilos de liderança. As amostras de estudo tipicamente consistiram em mulheres executivas, de diversos setores. Verifica-se um aumento das publicações nesta matéria; ainda assim, são propostas recomendações para futuras investigações.
\end{abstract}

Palavras-Chave: Liderança feminina, Género, Revisão de literatura

Abstract: Leadership emerges as a widely studied topic in national and international scientific publications. In this sense, it is important to find out if the leadership in the feminine deserves equal prominence. Our objective was to analyze the scientific production published in the biblioteca online do conhecimento (b-on) between 2010 and 2017. As a result of the limitation of the research using the keywords "leadership", "feminine" and "genre", 20 articles were analyzed. Most of the studies were descriptive, qualitative, exploratory and cross-sectional, with data collection to be effected through interviews and content analysis

\footnotetext{
1 Mestranda em Gestão na Universidade Católica Portuguesa - Viseu. E-mail: sandrinarsobral@gmail.com

${ }^{2}$ Doutorada em Psicologia. Professora Auxiliar da Universidade Católica Portuguesa Viseu. E-mail: cribeiro@viseu.ucp.pt
} 
being the method of extracting information. The studies focused on the difficulties of women's ascension to positions of superior hierarchies as well as their characteristics and leadership styles. Study samples typically consisted of executive women from various sectors. There is an increase of publications in this matter; nevertheless, recommendations are proposed for future investigations.

Key-words: Female leadership, Genre, Literature review

\section{INTRODUÇÃO}

A liderança pode ser definida como um processo de influência, por parte de um detentor de determinadas habilidades (comunicação, conhecimento, relacionamento, por exemplo), aplicada de forma individual ou coletiva, orientada para o alcance das necessidades e objetivos organizacionais (Ferreira, Marques, Reis, \& Santos, 2010; Rego, 1998; Reis \& Silva, 2012).

Historicamente os homens têm vindo a predominar em posições de liderança nas organizações, o que não lhes confere maior vantagem face às mulheres no desempenho de papéis de liderança. Existem características essenciais num bom líder que se encontram mais facilmente no género feminino que no masculino, ao adotarem um estilo mais democrático, de encorajamento e envolvimento, partilha de poder e de informação e desenvolvimento da equipa (Teixeira, 2013).

Segundo o Relatório de Desigualdade Global de Género 2017, do World Economic Forum, apesar dos esforços, a paridade de género continua a ser uma miragem na maioria dos 144 países que acompanha. Portugal surge na posição $33 .^{\circ}$, com uma evolução positiva face a 2015 (posição 39..$^{\circ}$ ), regressando a níveis de igualdade de género de 2006. Concretamente, no eixo da participação e oportunidades na economia, onde são analisados os salários, participação e liderança de género, os resultados revelam-se animadores, ainda assim aquém do desejável, fixando-se na posição $35 .^{\circ}$ em 2017, contra 46. ${ }^{\circ}$ em 2015 (World Economic Forum, 2015, 2017).

Na realidade, a participação feminina tende a diminuir à medida que aumenta a hierarquia de responsabilidades nas organizações (Nogueira, 2006). Em Portugal, o género feminino continua sub-representado, ao ocuparem 12,2\% dos lugares nos conselhos de administração das empresas cotadas em Bolsa, apesar de se ter registado uma evolução positiva, no período de 2011 a 2016, com uma duplicação percentual (Informa D\&B, 2018). 
Face ao exposto, objetivou-se analisar a produção científica efetuada desde o início da presente década, no período de 2010 a 2017, sobre liderança feminina. Para este estudo de metanálise foram analisados de forma sistemática 20 artigos empíricos, disponibilizados na biblioteca online do conhecimento ( $b$-on) com recurso às palavras-chave "liderança", "feminina" e "género". A recolha de dados foi efetuada tendo em conta uma grelha para análise de critérios.

\section{A LIDERANÇA NO FEMININO}

\section{Participação feminina no mercado de trabalho}

Num passado ainda recente, as funções da mulher reportavam-se ao cuidado da casa e dos filhos, enquanto o homem era visto como o sustento económico da família, originando uma relação de dependência (Cappelle, Brito, Melo, \& Vasconcelos, 2006). Era evidente a divisão entre as esferas pública e privada, baseada em diferentes aptidões e objetivos (Abreu \& Meirelles, 2012; Thimóteo, Zampier, \& Stefano, 2015), onde as mulheres não tinham acesso ao mercado de trabalho e o sustento era garantido com o casamento (Andrade, 2013).

Questionando a sua posição na sociedade, a figura feminina começou a caminhar no espaço laboral no sentido da sua emancipação económica e social. Contudo, a sua participação estava estritamente direcionada a funções menos qualificadas, ao serem recrutadas para a indústria têxtil. Estas funções eram caraterizadas pela exploração humana, onde eram longos os horários de trabalho e a diferença salarial era mais que evidente, tendo sido o mote para a contestação e legitimação da igualdade de direitos (Andrade, 2013; Mestre, 2004).

$\mathrm{O}$ ingresso em funções mais qualificadas evoluiu de forma lenta e gradual, começando por exercer funções como empregadas de escritório, como enfermeiras ou como professoras do então designado ensino primário (Araújo, 2001). Segundo Besse (2000), estas profissões não colidiam com a função de dona de casa e de cuidadora do(s) filho(s) e daí serem destinadas ao género feminino. Deste modo, estabeleciam-se profissões segundo o género, tendo em conta as responsabilidades definidas na sociedade (citado por Thimóteo et al., 2015).

Só no final da década de 70 do século XX é que as mulheres começam a alcançar posições hierárquicas tradicionalmente ocupadas por homens, impulsionadas pela crescente industrialização onde as organizações teriam de se ajustar de forma mais competitiva e dinâmica (Quirino, 2012). 
Paralelamente, as mulheres investiram cada vez mais na sua formação universitária, alargando as áreas de estudo não só à educação e cultura mas também à advocacia, medicina e engenharia (Bruschini, 2007; Bruschini \& Puppin, 2004).

A crescente exigência de recursos humanos mais qualificados pelas empresas potenciava o género feminino a sobressair no mercado de trabalho (Kanan, 2010); ainda assim, apesar de alcançarem um nível de escolaridade superior, existia a clara conviç̧ão que as oportunidades de progressão na carreira e o alcance de posições de chefia estavam longe de ser igualitárias (Salvagni \& Canabarro, 2015).

Embora haja evidência de uma certa evolução positiva, ainda persiste a desigualdade de género, nomeadamente no que respeita à menor ocupação feminina de cargos no sentido ascendente da pirâmide hierárquica na organização e quanto à desigualdade salarial, mesmo com funções e responsabilidades idênticas (Abreu \& Meirelles, 2012; Nogueira, 2006).

\section{Barreiras à ascensão feminina}

A metáfora do "teto de vidro" ou glass ceiling, com uma primeira abordagem em 1986, ilustra as várias tentativas da ascensão feminina constantemente impedidas por barreiras invisíveis, todavia suficientemente fortes para impedir o progresso feminino. Surge como fenómeno presente nos mais variados estudos na tentativa de fornecer uma explicação à sua subsistência (Kottis, 1993; Marques \& Ferreira, 2015; Nogueira, 2006; Steil, 1977).

Já Eagly e Carli (2007) propõem uma nova metáfora, ao designar a ascensão feminina como um "labirinto", distinguindo-se da anterior abordagem quanto à possibilidade em atingir cargos de chefia, contudo de forma muito dificultada e com vários percursos a ultrapassar (citados por Henderson et al., 2016).

Numa publicação da Catalyst Newsletter, de julho de 2001, foram listadas determinadas barreiras, ordenadas de forma descendente, nomeadamente a falta de apoio por parte de um mentoring (orientação de pessoa mais experiente), a existência de compromissos pessoais e familiares, a exclusão na transmissão informal de informação, a falta de modelos inspiradores femininos, a dificuldade de aceitação por parte de líderes masculinos mais antigos, a ausência de oportunidades e consequente ausência de experiência em cargos de topo e os estereótipos e preconceitos acerca das características e capacidades femininas (Evans, 2014). 
Deste modo, a fraca representatividade de mulheres em cargos de liderança deve-se essencialmente a fatores culturais e comportamentais que, por competirem entre si, afetam tanto homens como mulheres. Pode eventualmente ser explicada pela dimensão masculinidade/feminilidade, ao serem definidos os papéis sociais para os géneros, cabendo aos homens a assertividade, dureza e foco no sucesso material e às mulheres a ternura, a modéstia e a preocupação (Loureiro \& Cardoso, 2008).

É nos setores da saúde, serviços socias e comércio que a presença feminina é mais notada, ao contrário de setores como a agricultura, construção e indústria. $\mathrm{O}$ setor bancário carateriza-se por uma representatividade satisfatória em direções intermédias; ainda assim, o mesmo não se verifica no topo da pirâmide hierárquica (Bertrand \& Hallock, 2011).

A discriminação de liderança no feminino não assenta apenas entre sexos opostos mas também entre as próprias mulheres. Segundo Kottis (1993), são apontadas duas explicações para este fenómeno: por um lado, quando a ascensão se desenrolou com a adoção de um "estilo de liderança masculino" nas organizações e, por outro, o sentimento de injustiça e até inveja no caso de mulheres mais novas ascenderem de forma fugaz, sem terem percorrido as mesmas contrariedades e dificuldades por que outras.

São reconhecidos certos avanços na participação feminina em cargos de liderança, muito por via das suas características diferenciadoras e potenciadoras do comprometimento dos liderados na prossecução dos objetivos de desempenho organizacional; contudo, ainda permanece muito enraizada a cultura masculina, obrigando à constante prova de valia para determinada posição (Thimóteo et al., 2015).

\section{Caraterísticas e estilos da liderança feminina}

Numa fase preliminar e no sentido de auspiciarem cargos de chefia, as mulheres não assumiam as suas próprias características, recorrendo à sua simulação por forma a irem ao encontro das características ditas masculinas. Estas características passavam pela indumentária, utilizando cores mais escuras e sóbrias, bem como uma menor expressividade no gesticular (Lucas, Pires, Andrade, Amorim, \& Fischer, 2010).

O estudo de Fletcher (2001, citado por Henderson et al., 2016) debruçou-se sobre esta questão de quase "fingimento feminino", aplicado a engenheiras norte americanas, e concluiu que "abdicam de valores femininos, como a compreensão, a comunicação e a habilidade de trabalhar de forma integrada, não por serem ineficazes, mas justamente por esses 
valores estarem associados ao feminino, ao relacional ou ao lado mais soft (i.e., subjetivo, suave) das práticas organizacionais." (p.494).

Surge na literatura uma panóplia de características intrinsecamente femininas que conduzem a diferenças na liderança de géneros, comummente potenciadoras de crescimento individual e agilidade organizacional. Podemos destacar as seguintes: empatia; cuidado e preocupação com a equipa de trabalho; atenção e aceitação dos demais; particular capacidade de resposta às necessidades e motivações dos subordinados; capacidade de comunicação; orientação para a ação; facilidade de adaptação à diversidade; maior potencial para lidar com sentimentos; capacidade de negociação e resolução de problemas baseada na empatia, racionalidade e emoções; e a promoção de sistemas de recompensa e de avaliação da equipa (Lima, Lima, \& Tanure, 2009; Marques \& Ferreira, 2015; Noor, Uddin, \& Shamaly, 2011; Teixeira, 2013).

A liderança feminina aposta na relação e partilha, encorajando os liderados à participação e envolvimento na organização, assemelhando-se a um estilo mais democrático. Ao contrário, os homens tendem a focar-se mais na tarefa, ao ditar ordens a executar pelos liderados, assumindo um estilo autocrático (Eagly, 1995; Eagly \& Carli, 2003; Eagly \& Johnson, 1990; Stelter, 2002).

Em contraste, dois estudos realizados pelo Management Research Group (1999) e pelo Hagberg Consulting Group (1998) afirmam que é um mito acreditar que as mulheres são mais democráticas que os homens, dada a análise e planeamento estratégico que incutem ao negócio fruto da persistência nas tarefas e resultados (Evans, 2014).

Surge igualmente na literatura a liderança feminina associada ao conceito de liderança transformacional, fruto da capacidade de tornar os objetivos individuais numa perspetiva de equipa, incentivando a partilha e a comunicação através do empowerment dos subordinados. Por outro lado, os líderes masculinos tendem a adotar um estilo de liderança mais do tipo transacional (Buttner, 2001; Eagly \& Carli, 2003).

São invocados, como principais argumentos utilizados pelas empresas para a contratação de mulheres para cargos mais elevados, a capacidade dinâmica na conciliação da vida profissional e pessoal, a facilidade de adaptação ao ambiente e à cultura organizacional (Helfat, Harris, \& Wolfson, 2006) e o investimento crescente no desenvolvimento do capital humano (Henderson et al., 2016). Adicionalmente, ao nível financeiro, Hadary e Henderson (2012) verificaram maior retorno do investimento em 
empresas lideradas por mulheres, com um impacto económico e financeiro muito representativo (citados por Ong \& Tan, 2013).

\section{Metodologia}

A revisão da literatura foi efetuada por consulta à biblioteca do conhecimento online (b-on) com uma delimitação temporal de 2010 até 2017. As palavras-chave utilizadas foram "liderança", "feminina" e "género", tendo sido excluídos temas como desporto, ambiente escolar, religião e saúde pelas particularidades que apresentam. Foram ainda considerados apenas os artigos com uma componente teórica e empírica, simultaneamente, resultando numa seleção de 20 artigos publicados em revistas académicas.

A recolha de dados foi efetuada tendo em conta uma grelha para análise de critérios, contemplando a designação da revista, ano de publicação, autoria, objetivo(s) de estudo, o desenho de investigação com a identificação da amostra e instrumentos de recolha de dados utilizados, principais resultados e limitações.

\section{Resultados}

A investigação sobre a liderança feminina apresentou uma crescente evolução desde do início da presente década. Na segunda metade do período em análise, de 2014-2017 (inclusive), foram publicados 14 artigos, contra 6 artigos na primeira metade, no período de 2010-2013 (inclusive). O biénio 2016/2017 registou maior número de publicações, totalizando 8 artigos, contra 1 artigo em 2010/2011.

A partir da análise mais detalhada dos artigos, procedeu-se à sua classificação em seis categorias, conforme mostra a Tabela I. Todos os artigos foram enquadrados em pelo menos um subtema, podendo gerar múltiplas classificações devido à existência de objetivos de estudo vários.

A revisão identificou a prevalência de determinados assuntos, nomeadamente as barreiras, dificuldades e desafios à ascensão feminina, a definição de um perfil de líder suportando-se das características intrínsecas e singulares, a identificação de um estilo de liderança baseado nos estilos/abordagens expostos na literatura aliado a fatores comportamentais, bem como a implicação, eficácia e eficiência organizacional e efeitos sobre o bem-estar dos subordinados.

Não existe tendência relativamente às revistas alvo de publicação, com todos os artigos a serem divulgados em meios distintos. Não obstante, é 
possível aferir que são maioritariamente publicações na área da gestão, economia e psicologia.

Em termos de localização, a maioria dos estudos foram realizados no Brasil, com 10 artigos analisados (50\% no total), seguido de Portugal com 4 artigos e diversos países com menos expressão, cerca de um artigo por país, como os Estados Unidos da América, República da Macedónia, Espanha, Nigéria, França e Malásia.

Quanto à natureza das organizações alvo de análise, destaca-se o setor privado com 14 estudos, seguido do setor público e privado com 4 e, por último, o setor público objeto de 2 estudos.

Tabela I

Subtemas para categorização de artigos sobre liderança feminina

\begin{tabular}{|c|c|c|c|}
\hline Subtemas & Descrição & $\begin{array}{l}\mathrm{N}^{\circ} \text { de } \\
\text { artigos }\end{array}$ & $\begin{array}{l}\text { Exemplo de } \\
\text { artigos }\end{array}$ \\
\hline $\begin{array}{l}\text { Ascensão } \\
\text { feminina }\end{array}$ & $\begin{array}{l}\text { Barreiras, desafios, } \\
\text { desigualdades, superação e } \\
\text { fatores de empowerment. }\end{array}$ & 8 & $\begin{array}{l}\text { Saraiva } \\
(2017)\end{array}$ \\
\hline Perfil de líder & $\begin{array}{l}\text { Caraterísticas e traços de } \\
\text { personalidade. }\end{array}$ & 7 & $\begin{array}{c}\text { Thimóteo, } \\
\text { Zampier e } \\
\text { Stefano } \\
(2015)\end{array}$ \\
\hline $\begin{array}{l}\text { Estilos de } \\
\text { liderança }\end{array}$ & $\begin{array}{l}\text { Perfil de liderança, } \\
\text { comportamento organizacional e } \\
\text { relação com subordinados. }\end{array}$ & 6 & $\begin{array}{c}\text { Montes e } \\
\text { Roca (2016) }\end{array}$ \\
\hline $\begin{array}{c}\text { Implicação } \\
\text { organizacional }\end{array}$ & $\begin{array}{l}\text { Desafios pós promoção e } \\
\text { perceção dos subordinados. }\end{array}$ & 3 & $\begin{array}{c}\text { Glass e } \\
\text { Cook (2016) } \\
\end{array}$ \\
\hline $\begin{array}{c}\text { Eficácia e } \\
\text { Eficiência } \\
\text { organizacional }\end{array}$ & $\begin{array}{l}\text { Influência de fatores } \\
\text { socioculturais e mediação de } \\
\text { conflitos. }\end{array}$ & 2 & $\begin{array}{c}\text { Milenkovsk } \\
\text { a, } \\
\text { Markovska } \\
\text { e } \\
\text { Nikolovski } \\
(2017) \\
\end{array}$ \\
\hline Bem-estar & $\begin{array}{l}\text { Trabalho e bem-estar dos } \\
\text { subordinados. }\end{array}$ & 1 & $\begin{array}{c}\text { Sousa } \\
(2015)\end{array}$ \\
\hline
\end{tabular}

Quando se analisam os setores predominantes, verifica-se que os autores optaram por diversificar, com 15 estudos a incluir diversos setores em simultâneo como: indústria, educação, comércio, serviços financeiros e contabilidade e seguros. Os restantes optaram por um único contexto setorial, direcionado ao poder político local (em Portugal), publicitário, direito privado e empreendedorismo.

$\mathrm{Na}$ realização do estudo empírico é relevante verificar a composição da amostra, nomeadamente quanto ao tipo, número de 
elementos, profissão e género. Relativamente ao tipo de amostra verificase um equilíbrio na seleção, quanto à forma aleatória ou não aleatória, dependendo do instrumento utilizado. O número de elementos é variável, mais uma vez consoante o instrumento utilizado. Para a aplicação de entrevistas, naturalmente a quantidade é menor, explicada pela possibilidade e facilidade de análise do respetivo conteúdo, a variar entre os 4 e 12 elementos. Relativamente à aplicação de questionários, a amplitude dos dados é maior, variando entre os 52 e 572 elementos. Porém, ressalva-se a pertinência do conhecimento da representatividade da amostra na população, oculto na grande maioria dos estudos. A maioria dos inquiridos ocupa cargos de liderança nas organizações, seguindo-se os restantes trabalhadores. As entrevistas foram realizadas, única e exclusivamente, a elementos do género feminino. Foram apenas analisadas as opiniões masculinas, por via da aplicação de questionário e somente a subordinados, não sendo questionados líderes masculinos.

De forma unânime, os estudos são descritivos e transversais; contudo, apresentam particularidades, descritas na Tabela II. Relativamente ao tipo de estudo, foram encontrados estudos quantitativos, qualitativos e mistos (quantitativos e qualitativos). A abordagem maioritariamente adotada foi a qualitativa (55\%), seguida da quantitativa $(25 \%)$ e a mista $(20 \%)$. Adicionalmente, $35 \%$ dos estudos envolveram um caráter exploratório. Foi efetuado apenas um estudo correlacional por forma a averiguar a relação entre as práticas de liderança e as implicações organizacionais.

Com comportamento idêntico, a recolha de dados foi efetuada, maioritariamente, por via da elaboração de entrevistas (55\%), seguida da aplicação de questionários (online e em suporte papel, com 25\%) e a aplicação simultânea dos dois instrumentos (20\%). Em apenas 2 estudos foi utilizado um grupo focal como método de recolha de dados. Relativamente ao método utilizado para a análise de dados, surge a análise estatística, via Excel ou Statistical Package for the Social Sciences - SPSS, para tratamento de dados conseguidos por questionários. O método de análise utilizado para extrair informação das entrevistas realizadas foi a análise de conteúdo.

A apresentação de limitações ao estudo proporciona maior validade e confiabilidade ao processo de investigação desenvolvido. Dos 20 estudos analisados, apenas 9 apontaram limitações. Na sua maioria, apresentaram mais do que uma limitação, associada genericamente à incapacidade de generalização de resultados e à seleção/composição da amostra. A utilização da inferência estatística foi residual, gerando 
incapacidade dos autores em replicar os resultados conseguidos na amostra para a população. A amostra foi a limitação mais evidenciada, em 7 estudos, no que respeita à constituição de elementos de determinado género, cargo, empresa e contexto.

Os estudos à volta da liderança feminina surgem ainda escassos, estando patenteados os principais resultados dos artigos analisados na Tabela III. As investigações circundam em torno essencialmente de duas temáticas: por um lado a apresentação dos obstáculos que são necessários ultrapassar para que a mulher ganhe maior poder e representatividade nas posições hierárquicas de topo e, por outro lado, a apresentação de uma série de características das líderes femininas. Mesmo quando os objetivos de estudo não definem estas temáticas como prioridade, os autores tendem a apresentá-las pela importância que lhes é atribuída.

É apontado ao género feminino uma dimensão mais relacional, de proximidade com a equipa e na aposta do envolvimento do coletivo à tomada de decisão. Neste sentido, a liderança feminina é associada aos estilos/abordagens transformacional, situacional, participativo ou democrático (Montes \& Roca, 2016; Salvagni \& Canabarro, 2015), que Montes e Roca (2016) apelidam de liderança ideal, atualmente.

Há evidências de menor existência de conflitos numa organização quando a liderança é assumida por uma mulher, explicada pela sua capacidade de comunicação e relação com a equipa liderada (Moller \& Gomes, 2010). Já no que respeita à promoção do bem-estar dos colaboradores, não há evidências significativas da prevalência feminina (Sousa, 2015).

A eficiência e a eficácia organizacional são potenciadas pelo instinto feminino e a centralização de trabalhadoras afeta positivamente o desempenho organizacional, evidenciado pelo estudo de Abolade (2014). 
Tabela II

Tipo de estudo, método de recolha e análise de dados

\begin{tabular}{|c|c|c|c|c|c|c|c|c|c|c|c|}
\hline \multirow[b]{2}{*}{ Autor(es) } & \multicolumn{5}{|c|}{ Tipo de estudo } & \multicolumn{4}{|c|}{$\begin{array}{c}\text { Método de recolha } \\
\text { de dados }\end{array}$} & \multicolumn{2}{|c|}{$\begin{array}{l}\text { Método de } \\
\text { análise de } \\
\text { dados }\end{array}$} \\
\hline & & 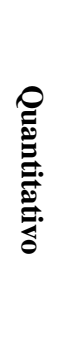 & 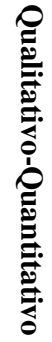 & 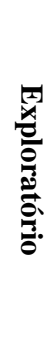 & 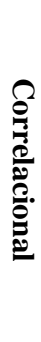 & 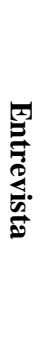 & 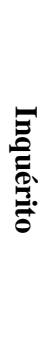 & 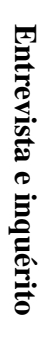 & 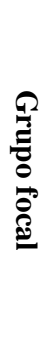 & 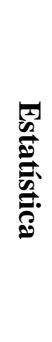 & 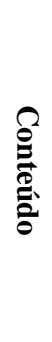 \\
\hline
\end{tabular}

(2017)

\begin{tabular}{lccccc}
\hline $\begin{array}{l}\text { Spricigo } \\
(2017)\end{array}$ & $\checkmark$ & $\checkmark$ & $\checkmark$ & $\checkmark$ \\
\hline Milenkovska, & $\checkmark$ & & & & \\
\hline
\end{tabular}

Markovska e

Nikolovski

(2017)

\begin{tabular}{lllll}
\hline Vasconcelos, & $\checkmark$ & $\checkmark$ & $\checkmark$ & $\checkmark$
\end{tabular}

Oliveira e

Fernandes

(2017)

\begin{tabular}{llllll}
\hline Glass e Cook & $\checkmark$ & & $\checkmark$ & $\checkmark$ & \\
$(2016)$ & & & & & \\
\hline Nunes e & $\checkmark$ & & $\checkmark$ & $\checkmark$
\end{tabular}

Mota (2016)

Henderson,

Ferreira,

Marcos e

Dutra (2016)

\begin{tabular}{lllll}
\hline Montes e & $\checkmark$ & $\checkmark$ & $\checkmark$ \\
Roca (2016) & & & & \\
\hline Salvagni e & $\checkmark$ & $\checkmark$ & $\checkmark$ & $\checkmark$
\end{tabular}

Canabarro

(2015) 


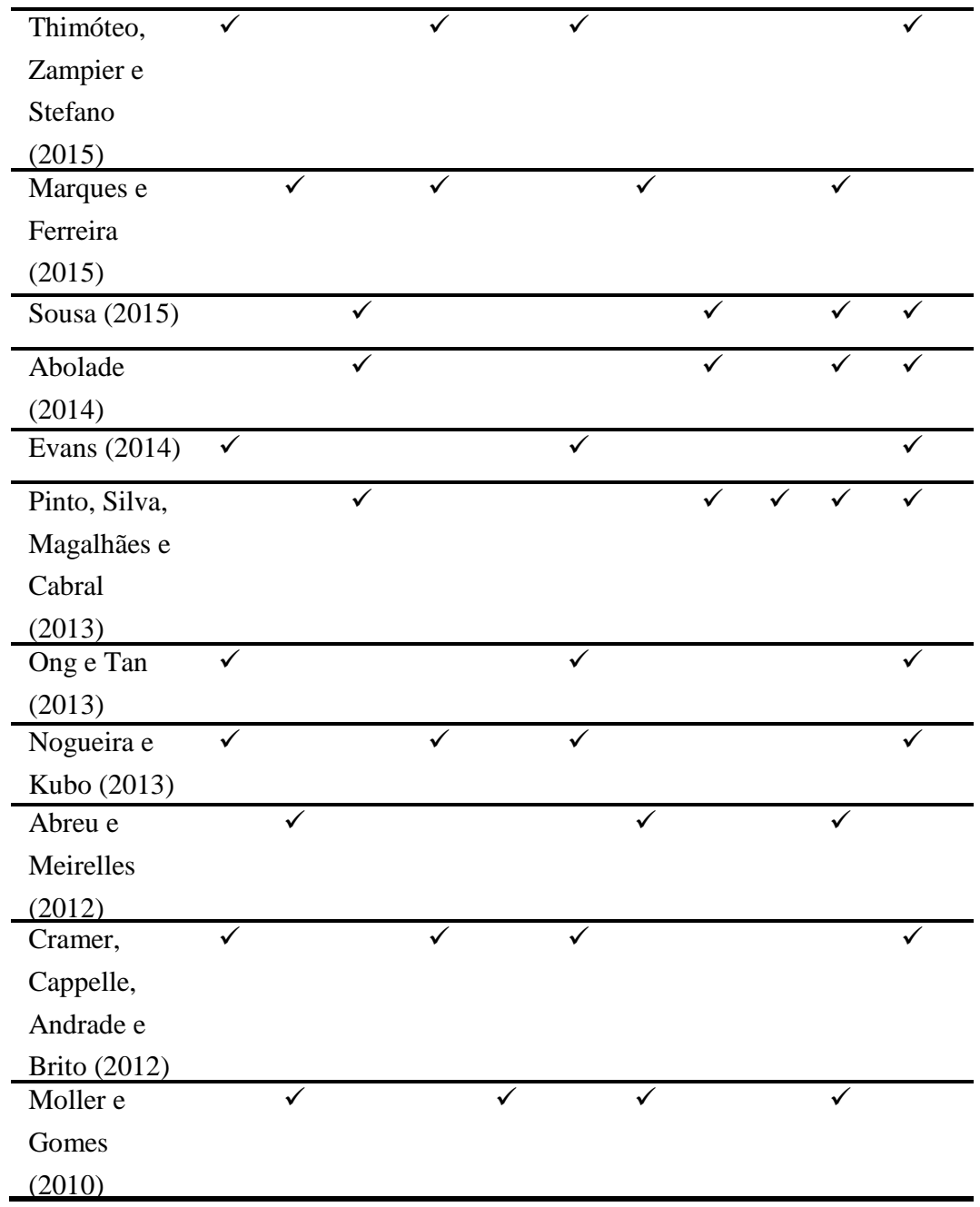

Apenas um estudo analisou os desafios que enfrentam na póspromoção, a partir da análise de uma base de dados Fortune 500 e de entrevistas a executivas, concluindo que as mulheres são mais propensas a serem promovidas a posições de liderança de alto risco e, frequentemente, não têm o apoio ou a autoridade para atingir os seus objetivos estratégicos. Como resultado, as líderes tendem a permanecer menos tempo no cargo, em comparação com os colegas do sexo masculino (Glass \& Cook, 2016). 


\section{Discussão dos resultados}

Esta revisão descritiva da literatura usou uma combinação de termos de pesquisa aplicada na base de dados eletrónica $b$-on. A análise iniciou-se com a leitura do resumo e dos principais resultados e conclusões, excluindo primeiramente todos os artigos apenas de revisão de literatura ou de metanálise, desde 2010. Não se descarta a possibilidade de não terem sido contempladas algumas publicações alvo de interesse que não se enquadravam nas palavras-chave escolhidas. Foram ainda excluídos estudos em contexto religioso, escolar, desportivo e saúde, dadas as características próprias subjacentes a cada área. A independência da autoria foi assegurada e a análise foi elaborada de duas formas: em primeiro lugar a redação da evolução dos conceitos através da consulta das várias revisões de literatura contidas nos estudos e, em segundo lugar a organização por via de tabela dos principais dados extraídos dos estudos.

Verifica-se uma quantidade crescente de estudos encarando temáticas mais diversificadas, onde os tópicos de investigação são amplamente definidos. Porém, é dada maior ênfase à listagem de obstáculos e características femininas e o seu impacto na liderança.

Existe uma clara predominância de investigações realizadas em contexto brasileiro, cerca de metade, embora Portugal esteja representado por 4 artigos. Nestes pretendeu-se analisar a representatividade no contexto político e em diversos outros setores, a perceção dos colaboradores no seu bem-estar e o impacto na implicação organizacional quando a liderança é exercida por mulheres.

A tipologia de estudo é predominantemente descritiva, podendo acarretar interesse adicional a realização de estudos correlacionais, por forma a relacionar a liderança feminina com a motivação dos colaboradores, mudança organizacional, inovação ou responsabilidade social, por exemplo. Por outro lado, as características femininas foram amplamente listadas; não obstante, instigam-se estudos correlacionais das suas implicações na cultura organizacional. A generalização dos resultados também se mostrou comprometida uma vez que a utilização da inferência estatística foi escassa. A amostra utilizada para os vários estudos empíricos contemplava maioritariamente participantes do género feminino, pelo que a inclusão de líderes masculinos poderia originar resultados distintos.

Normalmente é dado maior enfoque à pré nomeação a um cargo de chefia, surgindo com menos destaque a pós nomeação; deste modo, seria interessante apresentar uma evolução longitudinal do percurso profissional feminino. 
Tabela III

Principais resultados dos estudos revisados

\begin{tabular}{cl}
\hline \multicolumn{1}{c}{ Autor(es) } & \multicolumn{1}{c}{ Principais Resultados } \\
\hline \multirow{3}{*}{ Saraiva (2017) } & $\begin{array}{l}\text { A presença feminina no poder local, em Portugal, é } \\
\text { escassa, em parte explicada por barreiras pessoais e } \\
\text { materiais, colocando-as elegíveis para o exercício de } \\
\text { cargos de poder político. }\end{array}$ \\
\hline
\end{tabular}

A barreira cultural, a falta de tempo para qualificação profissional, o pouco reconhecimento e os estereótipos

Spricigo (2017) surgem como principais impedimentos à ascensão feminina no Brasil. A capacitação técnica e interpessoal, fazer um bom trabalho e a conciliação família/trabalho surgem como fatores de empowerment.

\begin{tabular}{|c|c|}
\hline $\begin{array}{l}\text { Milenkovska, } \\
\text { Markovska e } \\
\text { Nikolovski (2017) }\end{array}$ & $\begin{array}{l}\text { A liderança feminina afeta diretamente a redução de } \\
\text { conflitos organizacionais por via da aplicação de métodos } \\
\text { alternativos. }\end{array}$ \\
\hline $\begin{array}{l}\text { Vasconcelos, Oliveira e } \\
\text { Fernandes (2017) }\end{array}$ & $\begin{array}{l}\text { No processo sucessório, as mulheres surgem em segunda } \\
\text { linha face aos sucessores masculinos, com necessidade de } \\
\text { fazerem prova das suas capacidades. }\end{array}$ \\
\hline Glass e Cook (2016) & $\begin{array}{l}\text { As mulheres tendem a assumir posições de liderança de } \\
\text { alto risco, com reduzido apoio e autoridade para atingir os } \\
\text { objetivos propostos, resultando num tempo menor de } \\
\text { permanência no cargo que o género oposto. }\end{array}$ \\
\hline Nunes e Mota (2016) & $\begin{array}{l}\text { As mulheres surgem como menos firmes e seguras, mais } \\
\text { próximas da equipa, mais humildes, mais responsáveis e } \\
\text { mais atenciosas. }\end{array}$ \\
\hline $\begin{array}{l}\text { Henderson, Ferreira, } \\
\text { Marcos e Dutra (2016) }\end{array}$ & $\begin{array}{l}\mathrm{O} \text { investimento em capital humano, a mudança de } \\
\text { identidade feminina e a presença de um mentor ou sponsor } \\
\text { são necessários à ascensão a posições executivas. }\end{array}$ \\
\hline Montes e Roca (2016) & $\begin{array}{l}\text { A liderança das criativas espanholas identifica-se com o } \\
\text { estilo efetivo, criativo, transformacional e democrático. }\end{array}$ \\
\hline $\begin{array}{l}\text { Salvagni e Canabarro } \\
\text { (2015) }\end{array}$ & $\begin{array}{l}\text { A construção e o sucesso na carreira implicam muito } \\
\text { estudo, esforço, autodesenvolvimento e o equilíbrio entre } \\
\text { família/trabalho ao desempenhar vários papéis - mulher, } \\
\text { mãe, esposa e gestora. }\end{array}$ \\
\hline $\begin{array}{l}\text { Thimóteo, Zampier e } \\
\text { Stefano (2015) }\end{array}$ & $\begin{array}{l}\text { A liderança feminina destaca-se pela maior sensibilidade } \\
\text { na interação com a equipa, procurando a conciliação por } \\
\text { meio de diálogo e de proximidade. }\end{array}$ \\
\hline $\begin{array}{l}\text { Marques e Ferreira } \\
(2015)\end{array}$ & $\begin{array}{l}\text { Fraca representatividade feminina na gestão de topo e } \\
\text { divergente consoante os setores de atividade, pese embora } \\
\text { as mulheres possuam indicadores de liderança idênticos } \\
\text { aos homens. }\end{array}$ \\
\hline Sousa (2015) & $\begin{array}{l}\text { Os colaboradores reagem de forma mais favorável à } \\
\text { presença de chefias femininas. A promoção do bem-estar } \\
\text { da equipa parece estar associada ao estilo de liderança e } \\
\text { não tanto ao género. }\end{array}$ \\
\hline Abolade (2014) & $\begin{array}{l}\text { O instinto feminino e a qualidade } \text { da liderança } \\
\text { (influenciada por fatores socioculturais) } \\
\text { promovem a }\end{array}$ \\
\hline
\end{tabular}


eficácia organizacional. A centralização da mulher afeta positivamente o desempenho organizacional.

$\mathrm{O}$ estilo e as características femininas surgem mais adequados atualmente do que no passado. São indícios a

Evans (2014) presença de um estilo transformacional e traços de personalidade como escuta ativa, empatia, comunicação e multitarefa, favorecendo a coesão da equipa e maior harmonização organizacional.

O perfil das mulheres líderes no município de Itajubá (Brasil) foi traçado como casadas ou solteiras, com família e filhos, possuem nível superior completo, trabalham no ramo industrial ou de serviço, procuram outros pontos de vista e preferem trabalhar em grupo, têm grande

Pinto, Silva, Magalhães e Cabral (2013) flexibilidade para trabalhar com resultados não satisfatórios e com padrões e regras, possuem um alto grau de persuasão, usam da intuição, ambicionam a realização profissional, presam a liberdade, só assumem grandes riscos em situações concretas, forte preocupação com as pessoas, onde o lado familiar está fortemente presente na vida profissional, contribuindo positivamente para o seu desempenho.

Contextos como o tipo de indústria, tipo de design e ambiente laboral, tamanho da equipa, cultura e estrutura

Ong e Tan (2013) organizacional e o poder e autoridade influenciam a perceção dos funcionários sobre a eficácia das líderes femininas.

Os sentidos da liderança para as mulheres executivas brasileiras são dados pela facilidade de comunicação, uso

Nogueira e Kubo (2013) da intuição para a tomada de decisões, utilização de equipas de trabalho mistas, transformação de metas em causas e a relação com a sua equipa, ao ser envolvida na tomada de decisão, inspiração, capacitação, estimulação e recompensa dos vários membros.

Na Administração Pública Federal (Brasil), as mulheres

Abreu e Meirelles não ocupam posições de poder mais elevadas estando (2012) afetas a cargos sociais, devido, em parte, à opção pela vida familiar e os reduzidos convites e contactos.

São identificadas três categorias de representações sociais das mulheres líderes sobre o que significa ser mulher no

Cramer, Cappelle, Andrade e Brito (2012) mundo dos negócios: a construção da nova identidade da mulher empresária, a alteração da conceção dos filhos em relação à imagem da mãe enquanto profissional e a concorrência da atividade profissional com a dedicação à família.

Não há diferenças significativas na implicação organizacional dos colaboradores que respondem mais favoravelmente ao líder feminino do que ao líder masculino. 


\section{CONCLUSÃO}

A presente revisão da literatura revelou uma tendência positiva na ocupação de cargos de liderança pelo género feminino, porém, caraterizado por um processo lento e aquém do desejável, fomentando um aumento de publicações neste âmbito. Deste modo, é necessário perceber que, e referindo Bardwick (1984, citado por Cramer et al., 2012, p. 57), "as mulheres não são melhores nem piores que os homens. Não são completamente diferentes deles, nem totalmente iguais". São-lhes reconhecidas características de líder - comunicação, carisma, competência e capacidade de relacionamento passível de influenciar e inspirar o comportamento dos subordinados - no entanto, parece persistir o glass ceilling. Impera-se o desenvolvimento e a gestão de carreira, priorizar questões relacionadas com a qualidade de vida no trabalho, a definição de uma quota para mulheres em cargos de liderança bem como a harmonização da vida pessoal e familiar com a profissional (Spricigo, 2017).

Para este estudo objetivou-se analisar os escritos publicados sobre a liderança feminina, entre 2010 e 2017. Foram identificadas temáticas vastamente abordadas e outras com necessidade de estudos adicionais no sentido averiguar uma relação de dependência ou independência, por via da aplicação de métodos correlacionais, anteriormente discutidos. Maioritariamente, os estudos revelaram-se descritivos, qualitativos, exploratórios e de cariz transversal, com a recolha a dados através de entrevistas e a análise de conteúdo como método de extração de informação.

Apresenta-se como limitação do presente estudo a filtragem efetuada, podendo, eventualmente, ter excluído artigos igualmente pertinentes. Por outro lado, o reduzido número de publicações revisadas e o curto período temporal assumido podem ser igualmente impactantes nos resultados alcançados.

Espera-se com este artigo, através da uma análise dos escritos de revisão empírica, fomentar futuras investigações sobre a liderança feminina, relacionando-a com outras variáveis estratégicas numa organização, como motivação, resolução de conflitos, inovação, mudança organizacional, responsabilidade social empresarial, entre outras igualmente relevantes. Adicionalmente, pretendeu-se ampliar a compreensão e particularidades da liderança no feminino numa perspetiva holística. 


\section{BIBLIOGRAFIA}

Abolade, D. A. (2014). Socio-Cultural factor as determinant of female leadership quality; implications for human resource development. Ege Academic Review, 14(1), 53-62.

Abreu, M. A. A., \& Meirelles, R. de L. (2012). Mulheres e homens em ocupaçãoo de cargos de direção e assessoramento superior (DAS) na carreira de especialista em políticas públicas e gestão governamental (EPPGG). IPEA - Instituto de Pesquisa Económica Aplicada.Rio de Janeiro.

Andrade, M. C. de M. (2013). O século XIX: O mundo burguês / O casamento / A nova mulher: O contexto histórico dos romances Madame Bovary, Ana Karenina, O Primo Basílio e Dom Casmurro. Evidência, 8(9), 63-80.

Araújo, A. M. C. (2001). Dossie género no trabalho. Cadernos Pagu, 17(8), 131-138.

Bertrand, M., \& Hallock, K. F. (2011). The gender gap in top corporate jobs. Industrial and Labor Relations Review, 55(1), 3-21.

Bruschini, C., \& Puppin, A. B. (2004). Trabalho de mulheres executivas no Brasil no final do século XX. Cadernos de Pesquisa, 34(121), 105138.

Bruschini, M. C. A. (2007). Trabalho e género no Brasil nos últimos dez anos. Cadernos de Pesquisa, 37(132), 537-572.

Buttner, E. H. (2001). Examining entrepreneurs' female management style: an application of a relational frame. Journal of Buisness Ethics, 29, 253-269.

Cappelle, M. C. A., Brito, M. J., Melo, M. C. de O. L., \& Vasconcelos, K. A. (2006). A produção científica sobre género na administração: uma meta-análise. EnANPAD, 30 Encontro Da ANPAD, Salvador, 1-17.

Cramer, L., Cappelle, M. C. A., Andrade, Á. L. S., \& Brito, M. J. de. (2012). Representações feminas da ação empreendedora: uma análise da trajetória das mulheres no mundo dos negócios. Revista de Empreendedorismo e Gestão de Pequenas Empresas - REGEPE, 1(1), 53-71.

Eagly, A. H. (1995). The science and politics of comparing women and men. American Psychologist, 50(3), 145-158.

Eagly, A. H., \& Carli, L. L. (2003). The female leadership advantage: An evaluation of the evidence. Leadership Quarterly, 14, 807-834.

Eagly, A. H., \& Johnson, B. T. (1990). Gender and leadership style: A meta-analysis. Psychological Bulletin, 108(2), 233-256.

Evans, D. P. (2014). Aspiring to leadership ... a woman's world? Procedia 
Social and Behavioral Sciences, 148, 543-550.

Ferreira, M. P., Marques, T., Reis, N., \& Santos, J. C. (2010). Gestão empresarial ( $\left.2^{\mathrm{a}} \mathrm{Ed}\right)$. Lisboa: Lidel- Edições técnicas, lda.

Glass, C., \& Cook, A. (2016). Leading at the top: Understanding women's challenges above the glass ceiling. Leadership Quarterly, 27(1), 51-63.

Helfat, C. E., Harris, D., \& Wolfson, P. J. (2006). The pipeline to the top: women and men in the top executive ranks of U.S. corporations. Academy of Management Perspectives, 20(4), 42-64.

Henderson, P. A., Ferreira, M. A. de A., \& Dutra, J. S. (2016). As barreiras para a ascensão da mulher a posições hierarquicas: um estudo sob a óptica da gestão da diversidade no Brasil. Revista Da Administração UFSM, 9(3), 489-505.

Informa D\&B. (2018). Participação fenminina na gestão das empresas em portugal. Lisboa. Acedido a 27 de março de 2018 em: http://biblioteca.informadb.pt/read/document.aspx?id=2554

Kanan, L. A. (2010). Poder e liderança de mulheres nas organizações de trabalho. Organização e Sociedade, 17(53), 243-257.

Kottis, A. P. (1993). Women in management: the "glass ceiling" and how to break it. Women in Management Review, 8(4), 9-15.

Lima, G. S., Lima, M. S., \& Tanure, B. (2009). Os desafios da carreira da mulher executiva no Brasil. II Encontro de Gestão de Pessoas e Relações de Trabalho.

Loureiro, P., \& Cardoso, C. C. (2008). O género e os estereótipos na gestão. Revista de Estudos Politécnicos, VI(10), 221-238.

Lucas, A. C., Pires, F. M., Andrade, S. M. De, Amorim, W. A. C. De, \& Fischer, A. L. (2010). Identificação de práticas de gestão voltadas à questão de género: um estudo a partir das melhores empresas para você trabalhar. Encontro Nacional da ANPAD - EnANPAD, Rio de janeiro, $1-17$.

Marques, T. G., \& Ferreira, C. M. (2015). Mulheres na gestão de topo: A problemática do gap de género e salarial. Revista Ibero-Americana de Estratégia, 14(1), 43-59.

Mestre, M. B. A. (2004). Mulheres do século XX: Memórias de trajetórias de vida, suas representações (1936-2000). Tese de Doutoramento, Curitiba, Universidade Federal do Paraná.

Milenkovska, V., Markovska, M., \& Nikolovski, L. (2017). Promotion : women leadership and alternative methods for resolving business conflicts and changes in the organization. UTMS Journal of Economics, 8(2), 183-194.

Moller, M. A. B., \& Gomes, J. F. da S. (2010). Quid Vincit? O impacto da 
liderança feminina na implicação organizacional. Análise Psicológica, 28(4), 683-697.

Montes, C., \& Roca, D. (2016). El liderazgo femenino en la creatividad publicitaria. Cuadernos. INFO, (39), 113-131.

Nogueira, E. C. O. R., \& Kubo, E. K. de M. (2013). Sentidos do exercício da liderança por mulheres executivas brasileiras. Revista de Gestão E Secretariado - GeSeC, 4(2), 114-133.

Nogueira, M. da C. de O. C. (2006). Os discursos das mulheres em posições de poder. Caderno de Psicologia Social do Trabalho, 9(2), 57-72.

Noor, M. Al, Uddin, I., \& Shamaly, S. S. (2011). Leadership style and emotional intelligence: a gender comparison. Annamalai International Journal of Business Studies \& Research, 3(10), 27-52.

Nunes, J. R., \&Mota, E.P. da. (2016). Análise das caraterísticas para a formação de líderesem uma gestão estratégica. Revista iPecege, 1(3/4), $93-125$.

Ong, I. F., \& Tan, E. M. (2013). Emplyoees' perception on leadership effectiveness of female leaders in work organisations. AFBE Journal, 6(2), 208-230.

Pinto, N. A., Silva M. K., Magalhães, M. G. de, \& Cabral, R. J. (2013). Perfil de mulheres líderes na cidade de Itajubá-Mg. IX Congresso de Excelência em Gestão, 1-18

Quirino, R. (2012). Trabalho da mulher no Brasil nos últimos 40 anos. Revista Tecnologia e Sociedade, 2, 90-102.

Rego, A. (1998). Liderança nas organizações (1 $1^{\text {a }}$ Ed). Aveiro: Universidade de Aveiro.

Reis, F. L. dos, \& Silva, M. J. R. (2012). Princípios de gestão (1 $\left.{ }^{\mathrm{a}} \mathrm{Ed}\right)$. Lisboa: Edições Sílabo, Lda.

Salvagni, J., \& Canabarro, J. (2015). Mulheres Líderes: As desigualdades de género, carreira e família nas organizações de trabalho. Revista de Gestão e Secretariado - GeSeC, 6(2), 88-110.

Saraiva, A.P. (2017). Liderança política no feminino as presidentes de câmara no poder local em Portugal. Faces da Eva, 37,41- 61.

Sousa, F. C. (2015). Percepção de diferenças atribuíveis ao género dos líderes na promoção do bem-estar nas empresas. Teoria E Prática Em Administração, 5(1), 105-129.

Spricigo, C. (2017). Gestão empresarial e ascenção feminina: um estudo de caso numa empresa da região do sul do Brasil. Repositório Institucional: UFSC.

Steil, A. V. (1977). Organizações, género e posição hierárquica compreendendo o fenómeno do teto de vidro. Revista de 
Administração, 32(3), 62-69.

Stelter, N. Z. (2002). Gender differences in leadership: current social issues and future organizational implications. The Journal of Leadership Studies, 8(4), 88-99.

Teixeira, S. (2013). Gestão das organizações (3 ${ }^{\mathrm{a}}$ Ed). Lisboa: Escolar Editora.

Thimóteo, P. M., Zampier, M. A., \& Stefano, S. R. (2015). Atuação feminina em cargos de liderança: a realidade de algumas empresas de uma cidade da mesorregião central do Paraná. Revista da Micro e Pequena Empresa, 9(1), 53-75.

Vasconcelos, A. C. V. H., Oliveira, M. F. de, \& Fernandes, V. D. C. (2017).

$\mathrm{O}$ processo de sucessão em diferentes combinações de género: um estudo comparativo de casos em empresas familiares de Monte Carmelo, MG. Revista de Administração, Contabilidade e Economia (RACE), 16(1), 203-226.

World Economic Forum. (2015). The Global Gender Gap Index 2015. Genebra. Acedido a 27 de março de $2018 \mathrm{em}$ :

http://www3.weforum.org/docs/GGGR2015/The Global Gender Gap Index 2015.pdf

World Economic Forum. (2017). The Global Gender Gap Report 2017. Genebra. Acedido a 27 de março de $2018 \mathrm{em}$ :

http://www3.weforum.org/docs/WEF_GGGR_2017.pdf 